mujer judeo-español Mazaltó o Mazalta [ = hebreo masal tov traducido al italiano con Fortunata (loc. cit.). Al señor Malkiel le corresponde el mérito de haber explicado el desmazalado cervantino; pero, por compromiso con Ascoli, ha embrollado el problema al admitir una contaminación de esta palabra española con el desmazalado judeorespañol. Hay que separar las dos palabras y los dos ambientes: ni creo en el juego de palabras atribuído a los judíos (no tenemos rastro del desmazelado portugués en judeorespañol) ni en la adopción "graciosa" de una palabra judía por los cristianos. Malkiel no ha sido tan perspicaz en psicología como en gramática comparada.

Un detalle: ¿cómo puede Malkiel afirmar que desmacelado 'marcidus, languidus' se encuentra en Nebrija, cuando lo ha consultado en una reimpresión de 1754 ? La reimpresión de Rubiños, 1778, señala desmacelado con asterisco, es decir que la palabra es un agregado del editor (quien pudo haberla tomado del texto de Nieremberg). La edición de Zeballos, 1776, no la trae.

LEO SPITZER.

\title{
LERDO
}

En otro artículo sobre una vieja crux etymologica, el español lerdo ( $\mathrm{Ph} 2$, págs. 289-302), Yakov Malkiel se opone, en actitud de Enfin Malherbe vint, a las doce explicaciones dadas antes que la suya, a la cual juzga impecable, tanto desde el punto de vista semántico como desde el fonético. Según Malkiel, de * $(\mathrm{g})$ le rít a re < glis 'lirón', con el sentido de 'dormir como un lirón' (cf. el verbo enlerdar documentado en 1513), el español formó un adjetivo post verbal: lerdo 'lento, perezoso".

Malkiel no ha tomado en cuenta las objeciones fundamentales que se le ocurren a cualquier hispanista: las formas en -itare son en general muy escasas en las lenguas románicas (MeYer-LüBKe, Rom. Gr., II, pág. 587) : así un grac(c)ita re aparece en español bajo la forma graznar, pero ihay acaso en español otras formas en itare derivadas de nombres de animales en el sentido de 'comportarse como tal o cual animal', como las latinas en -ulare ( $p$ ull ul a re) ? Necesitaríamos al menos encontrar ejemplos. Pero aún más importante que este último argumento me parecen mis reparos a la formación del supuesto adjetivo postverbal. Para lerdo, derivado de enlerdar, eslardar, etc., Malkiel da como paralelos cuerdo < acordar, recordar; firme < firmar, podre < podrir, entregue < entregar, y otros innumerables adjetivos; comp. también casos apenas diferentes: manso < mansedumne, mansedumbre < $\mathrm{m}$ a n s u èt ù $\mathrm{d}$ ine, y lezne < deleznar. Obsérvese que la mayoría de estos ejemplos contienen -e final, o bien -o. Los dos únicos casos en ro que cita Malkiel son manso y cuerdo. Pero el esp. manso no viene del esp. mansedumbre, sino que representa un románico mansus (REW) que es necesario, evidentemente, relacionar con el latín mansuess (ErnoutMeillet piensan en la influencia de mansus < $\mathrm{m}$ a n e $\mathrm{r}$ e); y cuerdo no procede de los compuestos acordar, recordar, sino que está construido sobre cordatus (REW), como pago se apoya en pagado (Diez): de modelo han servido casos como oso (< a u s u s) osado (< a u s a r e), y ya se sabe que el italiano ha desa. rrollado este tipo de participios "abreviados" (trovo=trovato). Así, pues, un lerdo < enlerdar no tiene paralelos (se esperaría más bien un postverbal enlerde, como los entregue, delezne, que el mismo Malkiel cita). Enlerdar, documentado en 1513, tiene muchas más probabilidades de derivar de lerdo, empleado por Juan Ruiz (por lo demás, como variante de lordo), que no al revés. Finalmente el asturiano desllergá (variantes telergá, celergá) 'hacer cosquillas', en que apoya Malkiel su hipótesis de un radical ler $\left({ }^{*} \mathrm{~g} l\right.$ le re $)$ al cual se agrega el sufjo-itare (enlerdar) o bien el sufijo-icare (desllergar), no tiene 
nada que ver con lerdo: el cambio semántico 'despertar del sueño' (de lirón) $>$ 'hacer cosquillas', es absolutamente improbable, pues la noción de 'hacer cosquillas' es tan elemental en todas las lenguas que se comprendería más bicn el proceso opuesto; y además, basta comparar desllergá, telergá, celergá con las formas italianas dileticare, tellekare, cellekare, citadas en REW, s.v. titillicare 'hacer cosquillas', para comprobar que estamos en presencia de reflejos de esta última palabra latina, tan sujeta a variaciones fonéticas como lo están en general las palabras que significan cosquillas (al. kitzeln, ingl. to tickle; cf. ta mbién $R E W, 4684$ : kat.l, gat.l, etc.).

LEO SPITZER.

\section{CIVIL 'CRUEL'}

Una curiosa prueba del influjo de Juan de Mena, más significativa aún que el eco literario de su poesía, la ofrece la historia semántica de la palabra civil. La última obra del poeta origina, en efecto, una nueva acepción que llega hasta nuestros días en contextos que repiten las asociaciones del pasaje primitivo.

El siglo xv conoce civil en sentido opuesto a criminal:

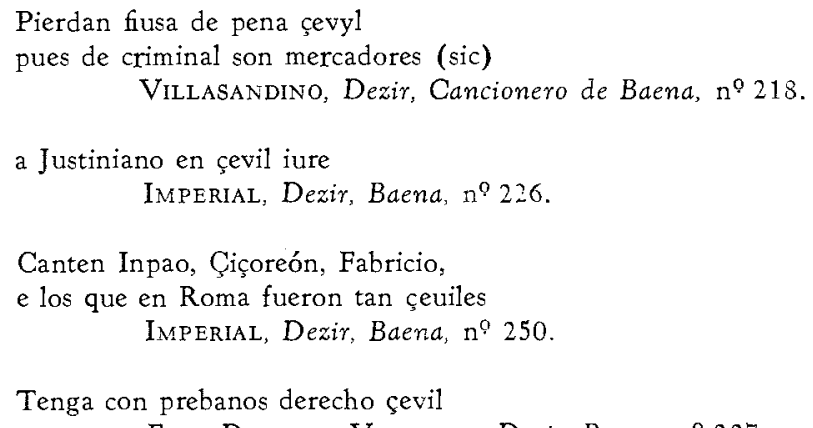

Fray Diego de Valencia, Dezir, Baena, no 227.

En tierra de moros un solo alcalde

libra lo çeuil e lo criminal.

Mena (?), Dezir sobre la justiçia, $6 a b$.

Hacia la misma época se conoce también civil en la acepción de "villano" (el hombre de la villa en contraste con el noble, habitante del castillo) y, por consiguiente, opuesto a noble:

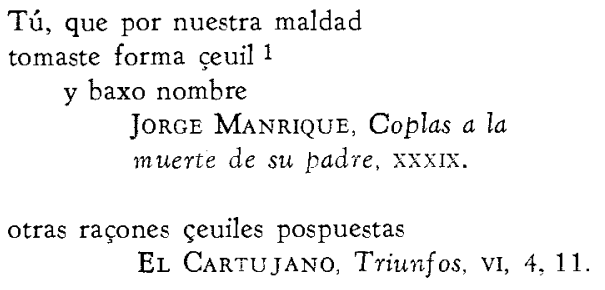

1 Así en el texto de Menéndez Pelayo, Antología de poetas líricos castellanos. B:blioteca clásica. Madrid, 1923. Tomo III, pág. 115. Las ediciones críticas de Foulché. Delbosc y de Cortina adoptan la lección seruil. 